(2) Open Access Full Text Article

ORIGINAL RESEARCH

\title{
Immediate Prescription of Oral Antihypertensive Agents in Hypertensive Urgency Patients and the Risk of Revisits with Elevated Blood Pressure
}

This article was published in the following Dove Press journal: Open Access Emergency Medicine

\section{Pungkava Sricharoen Aroonkamol Poungnil (D) Chaiyaporn Yuksen (D)}

Department of Emergency Medicine, Faculty of Medicine, Ramathibodi Hospital, Mahidol University, Bangkok, Thailand
Correspondence: Chaiyaporn Yuksen Department of Emergency Medicine, Faculty of Medicine, Ramathibodi Hospital, Mahidol University, Bangkok, Thailand

Tel +668947269II

Email chaipool0634@hotmail.com
Background: The steps and goals of treatment of hypertensive urgencies in the emergency department are not clear. The aim of this study was to compare the risk of revisits with elevated blood pressure in hypertensive urgency patients in the emergency department managed with and without oral antihypertensive medications.

Methods: This retrospective cohort study was conducted at the Emergency Medicine Department of Ramathibodi Hospital, a university-affiliated super tertiary care hospital in Bangkok, Thailand, from January 2018 to April 2020. A total of 692 hypertensive urgency patients were enrolled and categorized into oral antihypertensive drugs group and no oral antihypertensive drugs group.

Results: There were 298 patients in the antihypertensive drugs group and 394 patients in the no antihypertensive drugs group. There were no statistically significant differences of revisit rate with elevated blood pressure between oral antihypertensive drugs group and no antihypertensive drugs group within 1 day $(4.36 \%$ vs $6.35 \%, P=0.313)$ and 7 days $(32.55 \%$ vs $31.22 \%, P=0.742)$. The risk of revisits with elevated blood pressure was similar in both groups at 1 day $(\mathrm{OR}=0.58,95 \% \mathrm{CI}=0.26-1.27)$ and 7 days $(\mathrm{OR}=1.11,95 \% \mathrm{CI}=0.77-1.61)$. We found no case of major adverse cardiovascular events (MACE) in 1 day and a similar risk of MACE in 7 days $(\mathrm{OR}=0.23,95 \% \mathrm{CI}=0.01-4.18)$. Blood pressure control within 2 weeks was also not different $(\mathrm{OR}=0.76,95 \% \mathrm{CI}=0.45-1.30)$.

Conclusion: We have found no obvious evidence of benefit from oral antihypertensive agents in managing hypertensive urgencies in the ED. Oral hypertensive agents had no benefit in the reduction of blood pressure, no effect on reduction of ED length of stay, and blood pressure control within 2 weeks.

Keywords: hypertensive urgencies, emergency department, readmission

\section{Background}

Hypertension is one of the leading causes of death globally, approximately 7.5 million people, or $12.8 \%$ of all deaths. In Thailand, the rate of new cases in the past 3 years (2015-2017) increased from 916.89 per 100,000 population (540,013 people) to $1,353.01$ per 100,000 population $(813,485$ people). In 2017 , there were 133,953 deaths, or $2.11 \%$ of all hypertensive patients. ${ }^{1,2}$ Hypertension is one of the risk factors of cardiovascular disease and cerebrovascular disease, which are also major causes of global deaths. ${ }^{3}$

Hypertensive urgency is defined as acute elevated blood pressure with systolic blood pressure $\geq 180 \mathrm{mmHg}$ or diastolic blood pressure $\geq 110 \mathrm{mmHg}$ without 
evidence of end-organ damage. ${ }^{4}$ The patients can present with headache, dizziness, chest discomfort, epistaxis, or tinnitus. $^{5}$ There are more than 500,000 hypertensive patients per year, which are $2023.6 \%$ of all emergency department (ED) visits. 6,7

The steps and goals of treatment of hypertensive urgencies are not clear. Some patients could benefit from prescribing short-acting oral antihypertensive agents and being held for observation. ${ }^{4,8,9}$ Of the hypertensive urgency patients, 59.1-90.5\% received antihypertensive medications prior to discharge from the ED. ${ }^{10-12}$ The rate of readmission of hypertensive urgencies at 7 days was $7.53 \%$, at 30 days was $11.31 \%$, and at 90 days was $35 \%$; of that, $29 \%$ were readmitted with elevated blood pressure. The highest readmission rate was in the first 3 weeks. The factors associated with readmission were higher initial systolic blood pressure, tachycardia, known hypertension, presented with dyspnea, seizure, history of readmission, and history of drug abuse. ${ }^{13}$

The rate of Major Adverse Cardiovascular Events $(\mathrm{MACE})^{14}$ in hypertensive urgency patients presented at the primary care unit was not different between the group of patients who received antihypertensive medications and were sent home and the group of patients referred to the hospital at 7 days. $^{10}$ The patient who successfully controlled blood pressure at 2 weeks had lower blood pressure before discharge from the ED. ${ }^{12}$ The factors associated with blood pressure control were adherence to antihypertensive drugs, dietary lifestyle changes, and education level. Determinants of poor blood pressure control were age less than 60 years, use of three or more antihypertensive agents, non-adherence to medications and appointments, comorbidities of diabetes, peripheral arterial disease, stroke, obesity, history of hypertension, no previous diagnosis of heart failure, and no lipid-lowering treatment. $^{15-17}$

This study aimed to compare the risk of revisits with elevated blood pressure and other outcomes of hypertensive urgency patients in the emergency department managed with and without oral antihypertensive agents.

\section{Methods}

This study was a retrospective cohort study conducted at the Emergency Medicine Department of Ramathibodi hospital, a university-affiliated super tertiary care hospital in Bangkok, Thailand. We included the patients diagnosed with hypertensive urgency who visited the ED between January 2018 to April 2020. The data was collected from
Ramathibodi hospital database and Electronic Medical Records (EMR).

We registered the patients aged 18 years or older who visited the ED and were diagnosed with hypertensive urgency and had systolic blood pressure $\geq 180 \mathrm{mmHg}$ or diastolic blood pressure $\geq 110 \mathrm{mmHg}$ without evidence of end-organ damage. Pregnant women, trauma patients, psychiatric patients, patients who had surgery within 1 month, and patients who received antihypertensive medications prior to visiting the emergency department in 60 minutes were excluded.

Primary outcomes were 1-day and 7-day revisits with elevated blood pressure defined as systolic blood pressure $\geq 140 \mathrm{mmHg}$ or diastolic blood pressure $\geq 90 \mathrm{mmHg}$. Secondary outcomes were reduction of blood pressure, length of stay, 1-day and 7-day complications of hypertension assessed as major adverse cardiovascular events (MACE) including stroke, myocardial infarction, congestive heart failure, aortic dissection, 1-day and 7-day complication of antihypertensive agents, which is hypotension defined as systolic blood pressure $\leq 90 \mathrm{mmHg}$ or mean arterial pressure $\leq 65 \mathrm{mmHg}$. Successful blood pressure control is defined as systolic blood pressure $<140 \mathrm{mmHg}$ and diastolic blood pressure $<90 \mathrm{mmHg}$ within 2 weeks after discharge from ED.

According to Sánchez-Fabra et al, ${ }^{10}$ overall revisit rate of hypertensive urgencies was $7.53 \%$, and, according to STAT study, ${ }^{13}$ the revisit rate of hypertensive urgency patients who received antihypertensive medications was $3.02 \%$. STATA version 16.0 analysis software was used to calculate the sample size by employing two independent study groups with dichotomous data of primary outcome with alpha $=0.05$, power of sample $=70 \%$, the ratio of sample $=1: 1$. The calculated sample size was 692 (346 in antihypertensive agents group and 346 in no antihypertensive agents group).

The data were analyzed by STATA version 16.0. All study variables were compared between the antihypertensive agents and no antihypertensive agents groups by descriptive statistics. Categorical data were analyzed by the exact probability test. Continuous data were analyzed by independent $t$-test. The comparison of the risk of revisit and blood pressure control of exposure and non-exposure group with exact probability test were then analyzed by univariate logistic regression and adjusted confounders with multivariate logistic regression analysis and presented with odd ratios. The difference of blood pressure reduction and length of stay were analyzed by univariate linear 
regression and adjusted confounders with multivariate linear regression analysis and presented with a mean difference. Statistical significance was a $P$-value $<0.05$.

\section{Ethical Considerations}

This study was approved by the Faculty of Medicine, Committee on Human Rights Related to Research Involving Human Subjects, of Mahidol University's Ramathibodi Hospital (COA. NO. MURA2019/369). The ethics committee waived the need for informed consent due to the retrospective design and reviewing only the medical records. This study complied with the Declaration of Helsinki, and patient data confidentiality was maintained.

\section{Results}

During the study period, there were 1,690 patients visiting the ED diagnosed with hypertensive urgency, 782 met the inclusion criteria, of which 90 were excluded. The remaining total study sample of 692 patients were categorized into two groups: 298 patients in the antihypertensive agents group and 394 patients in the no antihypertensive agents group (Figure 1).

The mean age of the samples was $67.63 \pm 14.07$ years, and $69.8 \%$ were women. Most of the patients were known cases of hypertension (86.27\%), comorbidities, and history of hypertension were not different between both groups except for chronic kidney disease that was higher in no antihypertensive agents group $(8.05 \%$ vs $12.69 \%$, $P=0.007) ; 11.56 \%$ were asymptomatic patients, $17.92 \%$ presented with headache, $26.73 \%$ presented with dizziness, $6.65 \%$ with dyspnea, and $44.80 \%$ had other symptoms such as chest pain, palpitation, diarrhea, or fever. There were statistical differences in presenting symptoms between both groups. The antihypertensive agents group had higher mean systolic blood pressure, mean diastolic blood pressure, and lower heart rate; $205.22 \pm 19.51$ vs $194.31 \pm 15.19$ $\mathrm{mmHg}, \quad 101.73 \pm 16.35$ vs $94.06 \pm 14.35 \mathrm{mmHg}, 81.35$ \pm 16.35 vs $84.86 \pm 18.07$ beat $/ \mathrm{min}$, respectively (Table 1 ). In total, $95.52 \%$ of the patients were discharged from the ED, and $4.48 \%$ were admitted to the hospital. Of the 298 patients in the antihypertensive agent group, 58.39\% received hydralazine, $12.42 \%$ received captopril, and $26.51 \%$ received more than one drug.

The overall 1-day revisit rate was $6.79 \%$ (47 patients), $5.70 \%$ were in antihypertensive agents group, and $7.61 \%$ in the no antihypertensive agents group. Total revisit rate with elevated blood pressure was $5.49 \%$, and there was no statistically significant difference in the antihypertensive agents group and the no antihypertensive agents group (4.36\% vs $6.35 \%, P=0.313$ ). Revisiting mean systolic blood pressure and diastolic blood pressure were not different in both groups. No MACE was found within 1 day after discharge from the ED (Table 2).

Overall 7-day revisit was found in 296 patients $(42.77 \%), 40.94 \%$ were in the antihypertensive agents group, and $44.16 \%$ in the no antihypertensive agents group. Of all the patients who revisited with blood pressure $(31.79 \%)$, there was no difference between groups (32.55\% vs $31.22 \%, P=0.742)$. Revisiting means systolic blood pressure and diastolic blood pressure were different in both groups. Mean SBP was $165.46 \pm 29.73 \mathrm{mmHg}$ in the antihypertensive drug group and 153.30 \pm 24.72 $\mathrm{mmHg}$ in the no antihypertensive drug group $(P<0.001)$. Mean diastolic blood pressure was different in both groups, $84.81 \pm 16.67 \mathrm{mmHg}$ in the antihypertensive drug group and $79.64 \pm 13.90 \mathrm{mmHg}$ in the no antihypertensive drug group $(P=0.004)$. MACE was found in four patients $(0.58 \%)$, two with stroke, and two with heart failure, $0.34 \%$ were in the antihypertensive drug group, and $0.76 \%$ were in the no antihypertensive drug group $(P=0.638)$ (Table 2$)$.

The antihypertensive agents group had a similar risk of 1-day revisit as no antihypertensive agents group $(\mathrm{OR}=0.66,95 \% \mathrm{CI}=0.33-1.35)$, and also a similar risk of revisited with elevated blood pressure $(\mathrm{OR}=0.58$. 95\% $\mathrm{CI}=0.26-1.27)$. There was no statistically significant difference of 7-day revisit $(\mathrm{OR}=0.99,95 \% \mathrm{CI}=0.70-1.41)$, and no difference risk of 7-day revisit with elevated blood pressure $(\mathrm{OR}=1.11,95 \% \mathrm{CI}=0.77-1.61)$. The risk of MACE was not different in both groups $(\mathrm{OR}=0.23,95 \%$ $\mathrm{CI}=0.01-4.18$ ). (Table 3)

There were no differences in other outcomes of interest after being adjusted with potential confounders, as shown in Table 3 . The reduction of systolic blood pressure, diastolic blood pressure, changes of heart rate, and length of stay were not different in both groups: $-2.65 \mathrm{mmHg}(-1.22-6.51), 0.55$ $\mathrm{mmHg}(-1.45-2.56),-0.24$ beat/min $(-2.12-1.64)$, and -1.30 hours $(-3.80-1.21)$, respectively. There were no differences in changes of systolic and diastolic blood pressure at 1-day revisit of $21.51 \mathrm{mmHg}(95 \% \mathrm{CI}=-1.93-44.95)$, and $9.84 \mathrm{mmHg}(95 \% \mathrm{CI}=-2.01-21.69)$, respectively. There was no difference in changes of systolic and diastolic blood pressure at 7-day revisit, $7.61 \mathrm{mmHg}(95 \%$ $\mathrm{CI}=0.56-14.66)$, and $1.82 \mathrm{mmHg}(95 \% \mathrm{CI}=-1.46-5.09)$ (Table 4). 


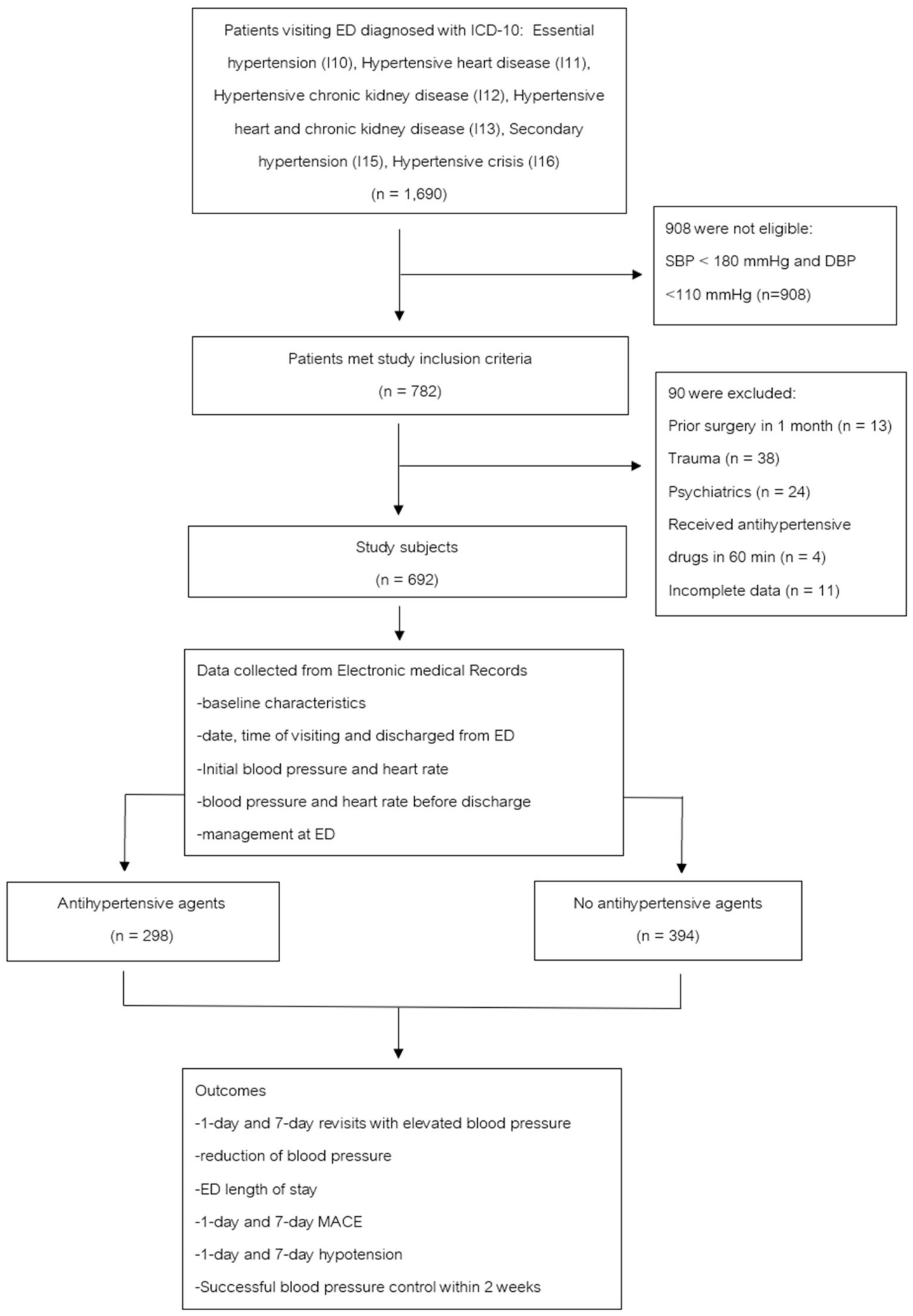

Figure I Flow diagram of study. 
Table I Baseline Characteristics of Patients with Hypertensive Urgency Categorized by Management as Antihypertensive Agents Group and No Antihypertensive Agents Group

\begin{tabular}{|c|c|c|c|c|}
\hline Characteristics & $\begin{array}{l}\text { Total Sample } \\
(n=692)\end{array}$ & $\begin{array}{l}\text { Antihypertensive } \\
\text { Agents Use } \\
(n=298)\end{array}$ & $\begin{array}{l}\text { No Antihypertensive } \\
\text { Agents Use } \\
(n=394)\end{array}$ & p value \\
\hline Age (years) & $67.63 \pm 14.07$ & $65 \pm 14.46$ & $69.52 \pm 13.48$ & $<0.001$ \\
\hline Female n (\%) & $483(69.80)$ & $208(69.80)$ & $275(69.80)$ & 1.00 \\
\hline \multicolumn{5}{|l|}{ Comorbidities n (\%) } \\
\hline Hypertension & $597(86.27)$ & $250(83.89)$ & $347(88.07)$ & 0.119 \\
\hline Diabetes mellitus & $255(36.85)$ & 99 (33.22) & I56 (39.59) & 0.095 \\
\hline Dyslipidemia & 353 (5I.0I) & I44 (48.32) & 209 (53.05) & 0.220 \\
\hline Coronary artery disease & $98(14.16)$ & $36(12.08)$ & $62(15.74)$ & 0.187 \\
\hline Chronic kidney disease & $207(29.91)$ & $73(24.50)$ & I 34 (34.0I) & 0.007 \\
\hline Cerebrovascular disease & $92(13.29)$ & $32(10.74)$ & $60(15.23)$ & 0.091 \\
\hline Peripheral artery disease & $3(0.43)$ & $2(0.67)$ & I $(0.25)$ & 0.580 \\
\hline Chronic lung disease & $74(10.69)$ & $24(8.05)$ & $50(12.69)$ & 0.062 \\
\hline \multicolumn{5}{|l|}{ Presentations } \\
\hline Asymptomatic n (\%) & $80(11.56)$ & $54(18.12)$ & $26(6.60)$ & $<0.001$ \\
\hline Headache n (\%) & $124(17.92)$ & $80(26.85)$ & $44(11.17)$ & $<0.001$ \\
\hline Dizziness n (\%) & $185(26.73)$ & $98(32.89)$ & $87(22.08)$ & 0.002 \\
\hline Dyspnea n (\%) & $46(6.65)$ & II (3.69) & $35(8.88)$ & 0.008 \\
\hline Others n (\%) & $310(44.80)$ & $80(26.85)$ & $230(58.38)$ & $<0.001$ \\
\hline $\mathrm{SBP}(\mathrm{mmHg})$ & $199.0 \pm 18.00$ & $205.22 \pm|9.5|$ & $194.31 \pm 15.19$ & $<0.001$ \\
\hline $\mathrm{DBP}(\mathrm{mmHg})$ & $97.36 \pm 15.70$ & $101.73 \pm 16.35$ & $94.06 \pm 14.35$ & $<0.001$ \\
\hline HR (beat/min) & $83.35 \pm 17.43$ & $81.35 \pm 16.35$ & $84.86 \pm 18.07$ & 0.009 \\
\hline \multicolumn{5}{|l|}{ Dispositions n (\%) } \\
\hline Discharge & $66 I$ (95.52) & 293 (98.32) & $386(93.40)$ & 0.001 \\
\hline Admission & 31 (4.48) & $5(1.68)$ & $26(6.60)$ & 0.001 \\
\hline
\end{tabular}

Abbreviations: SBP, systolic blood pressure; DBP, diastolic blood pressure.

Table 2 Unadjusted Outcomes of Antihypertensive Agents Use in Hypertensive Urgencies

\begin{tabular}{|c|c|c|c|c|}
\hline & Total $(n=692)$ & $\begin{array}{l}\text { Antihypertensive Agents Use } \\
(n=298)\end{array}$ & $\begin{array}{l}\text { No Antihypertensive Agents Use } \\
(n=394)\end{array}$ & $P$-value \\
\hline Reduction of SBP $(\mathrm{mmHg})$ & $33.22 \pm 26.61$ & $36.28 \pm 26.08$ & $30.90 \pm 26.80$ & 0.009 \\
\hline Reduction of DBP $(\mathrm{mmHg})$ & $13.06 \pm 14.75$ & $15.34 \pm \mid 4.93$ & $11.33 \pm 14.39$ & $<0.001$ \\
\hline Reduction of HR (beat $/ \mathrm{min}$ ) & $4.07 \pm 12.78$ & $3.55 \pm 13.40$ & $4.47 \pm 12.30$ & 0.352 \\
\hline LOS (hours) & $7.77 \pm 15.89$ & $4.9 \pm 8.34$ & $9.94 \pm \mid 9.51$ & $<0.001$ \\
\hline I-day revisit n (\%) & 47 (6.79) & $17(5.70)$ & $30(7.6 I)$ & 0.362 \\
\hline Revisit with $\mathrm{BP} \geq 140 / 90 \mathrm{mmHg}, \mathrm{n}(\%)$ & $38(5.49)$ & $13(4.36)$ & $25(6.35)$ & 0.313 \\
\hline SBP $(\mathrm{mmHg})$ & $163.79 \pm 29.82$ & $171.59 \pm 33.08$ & $159.37 \pm 27.40$ & 0.180 \\
\hline $\mathrm{DBP}(\mathrm{mmHg})$ & $84.70 \pm|7.7|$ & $89.41 \pm 76.89$ & $82.03 \pm 12.23$ & 0.173 \\
\hline MACE, n (\%) & $0(0)$ & $0(0)$ & $0(0)$ & NA \\
\hline 7-day revisit,n (\%) & $296(42.77)$ & $122(40.94)$ & $174(44.16)$ & 0.438 \\
\hline Revisit with $\mathrm{BP} \geq 140 / 90 \mathrm{mmHg}, \mathrm{n}(\%)$ & $220(31.79)$ & $97(32.55)$ & $123(31.22)$ & 0.742 \\
\hline SBP $(\mathrm{mmHg})$ & $|58.3| \pm 27.5 \mid$ & $165.46 \pm 29.73$ & $153.30 \pm 24.72$ & $<0.001$ \\
\hline $\mathrm{DBP}(\mathrm{mmHg})$ & $81.77 \pm 15.29$ & $84.81 \pm 16.6)$ & $79.64 \pm 13.90$ & 0.004 \\
\hline MACE, n (\%) & $4(0.58)$ & I $(0.34)$ & $3(0.76)$ & 0.638 \\
\hline
\end{tabular}

Abbreviations: SBP, systolic blood pressure; DBP, diastolic blood pressure; HR, heart rate; LOS, length of stay. 
Table 3 Outcomes of Antihypertensive Agents Use in Hypertensive Urgencies (Adjusted with Age Sex Comorbidities, Blood Pressure, and Heart Rate at First Visit, and Symptoms)

\begin{tabular}{|l|l|l|l|l|}
\hline & $\begin{array}{l}\text { Crude OR } \\
\mathbf{( 9 5 \% ~ C l )}\end{array}$ & P-value & Adjusted OR (95\% Cl) & P-value \\
\hline I-day revisit & $0.73(0.40-1.36)$ & 0.324 & $0.66(0.33-1.35)$ & 0.256 \\
BP $\geq 140 / 90 \mathrm{mmHg}$ & $0.67(0.34-1.34)$ & 0.260 & $0.58(0.26-1.27)$ & $0.99(0.70-1.4 I)$ \\
7-day revisit & $0.88(0.65-1.19)$ & 0.396 & $1.11(0.77-1.61)$ & 0.964 \\
BP $\geq 140 / 90 \mathrm{mmHg}$ & $1.06(0.77-1.47)$ & 0.709 & $0.23(0.01-4.18)$ & 0.570 \\
MACE & $0.44(0.05-4.24)$ & 0.477 & $0.76(0.45-1.30)$ & 0.321 \\
BP controlled in 2 weeks & $0.56(0.35-0.89)$ & 0.013 & 0.319 \\
\hline
\end{tabular}

Abbreviations: SBP, systolic blood pressure; DBP, diastolic blood pressure; HR, heart rate; LOS, length of stay; MACE, major adverse cardiovascular events.

Table 4 Outcomes of Antihypertensive Agents Use with Adjusted Difference (Adjusted with Age Sex Comorbidities, Blood Pressure, and Heart Rate at First Visit, and Symptoms)

\begin{tabular}{|c|c|c|c|c|}
\hline & $\begin{array}{l}\text { Crude Difference } \\
(95 \% \mathrm{Cl})\end{array}$ & $P$-value & Adjusted Difference $(95 \% \mathrm{Cl})$ & $P$-value \\
\hline $\mathrm{SBP}(\mathrm{mmHg})$ & $-5.37(-9.36--1.39)$ & 0.008 & $-2.65(-|.22-6.5|)$ & 0.180 \\
\hline $\mathrm{DBP}(\mathrm{mmH} \mathrm{g})$ & $-4.01(-6.22--1.81)$ & $<0.001$ & $0.55(-1.45-2.56)$ & 0.589 \\
\hline Reduction of heart rate $($ beat $/ \mathrm{min})$ & $0.91(-1.01-2.84)$ & 0.352 & $-0.24(-2.12-1.64)$ & 0.804 \\
\hline LOS (hours) & $-5.04(-7.40--2.68)$ & $<0.001$ & $-1.30(-3.80-1.21)$ & 0.311 \\
\hline \multicolumn{5}{|l|}{ I-day revisit } \\
\hline $\mathrm{SBP}(\mathrm{mmHg})$ & $12.22(-5.36-29.80)$ & 0.173 & $21.51(-1.93-44.95)$ & 0.072 \\
\hline $\mathrm{DBP}(\mathrm{mmHg})$ & $7.38(-3.05-17.81)$ & 0.166 & $9.84(-2.01-21.69)$ & 0.104 \\
\hline \multicolumn{5}{|l|}{ 7day revisit } \\
\hline $\mathrm{SBP}(\mathrm{mmHg})$ & $12.16(5.94-18.38)$ & $<0.001$ & $7.61(0.56-14.66)$ & 0.034 \\
\hline $\mathrm{DBP}(\mathrm{mmHg})$ & $5.17(1.67-8.66)$ & 0.004 & I.82 (-1.46-5.09) & 0.277 \\
\hline \multicolumn{5}{|l|}{ In 2 weeks } \\
\hline $\mathrm{SBP}(\mathrm{mmHg})$ & $9.71(4.79-14.64)$ & $<0.001$ & $4.09(-1.47-9.65)$ & 0.149 \\
\hline $\mathrm{DBP}(\mathrm{mmHg})$ & $4.49(I .7 I-7.28)$ & 0.002 & $0.55(-2.06-3.16)$ & 0.678 \\
\hline
\end{tabular}

Abbreviations: SBP, systolic blood pressure; DBP, diastolic blood pressure; HR, heart rate; LOS, length of stay.

For 398 patients with blood pressure recorded within 2 weeks after discharge from the ED, 163 patients were in the antihypertensive agents group, and 235 in the no antihypertensive agents group. We found that there were 115 patients $(28.89 \%)$ with successfully controlled blood pressure $<140 / 90 \mathrm{mmHg}$ within 2 weeks, $22.09 \%$ in the antihypertensive agents group, and $33.62 \%$ in the no antihypertensive agents group $(P=0.013)$. Mean systolic blood pressure was higher in the antihypertensive drug group $(158.75 \pm 25.07 \mathrm{mmHg}$ vs $149.03 \pm 24.37 \mathrm{mmHg}$, $P<0.001)$, mean diastolic blood pressure was different in both groups $(82.10 \pm 15.69 \mathrm{mmHg}$ in antihypertensive drug group vs $77.61 \pm 12.60 \mathrm{mmHg}, P=0.002$ ). There was no significant difference of blood pressure control within 2 weeks in either group $(\mathrm{OR}=0.76,95 \% \mathrm{CI}=0.45-1.30)$.
There were no differences in systolic and diastolic blood pressure within 2 weeks $(\mathrm{OR}=4.09,95 \% \mathrm{CI}=-1.47-9.65$; and $\mathrm{OR}=0.55,95 \% \mathrm{CI}=-2.06-3.16$, respectively).

\section{Discussion}

In this study, we found no significant differences in the risk of 1-day and 7-day revisits with elevated blood pressure between the oral antihypertensive agents group and the no antihypertensive agents group. Blood pressure reduction, length of stay, MACE, and blood pressure control within 2 weeks, complications of antihypertensive agents, were also not different in both groups.

We reported lower usage of oral antihypertensive agents in managing hypertensive urgency (298 in 692 patients, $43.06 \%$ ) than the previous study. ${ }^{11,20}$ We found 
a similar 1-day revisit rate as the previous study, but a 7-day revisit rate was slightly higher. This could be because of our emergency department protocol that does not allow emergency physicians (EP) to prescribe medications of more than 2 weeks duration, and the EP cannot make an appointment to any out-patient department in the hospital without a specialist consultant. So, practically after discharge, the patients with acute severe elevation of blood pressure, most of the EPs advised the patients to visit or make an appointment at the medicine or family medicine out-patient department within 2 weeks to get blood pressure control. We found that there were no statistically significant differences of the risk of 1-day and 7-day revisits with elevated blood pressure in hypertensive urgency patients managed by oral antihypertensive agents and patients managed without oral antihypertensive agents. These could be explained by the secondary outcomes we have found. We found that there were no differences in reduction of blood pressure before discharge from ED in both groups similar to a previous study, ${ }^{18}$ and no difference in blood pressure controlled within 2 weeks between both groups after adjusted outcomes with potential confounders. For complications of hypertensive urgency, we found no differences in MACE at 1-day and 7 -days in both groups. In comparison with Patel et al, ${ }^{10}$ a large cohort study of 58,535 samples that reported no significant difference of MACE in the group managing with sending home and referring to the hospital, this study showed similar results. We found the longer length of stay: 4.9 ( \pm 8.34$)$ hours in the medication group and 9.94 $( \pm 19.51)$ hours in no medication group than the previous study which demonstrated that $80.5 \%$ of the patients had ED time $\leq 4$ hours $^{11}$ as a result of co-occurring conditions in some patients that might lead to longer hours in ED, or delaying of management during the time of ED crowded. Yet, no complications of oral antihypertensive agents in managing hypertensive urgencies were found. One patient in an antihypertensive agent group received a combination of drugs revisited at 7 days with hypotension and was diagnosed with cellulitis with septicemia. The condition of sepsis could be the factors affecting the lowering of blood pressure in this patient rather than antihypertensive agents alone.

The results of this study supported the previous recommendations of hypertensive urgency management and latest European guideline of hypertension, ${ }^{4,19,20}$ they downgraded hypertensive urgencies to be managed as severe elevated blood pressure (grade 3 hypertension).
Unlike hypertensive emergencies that require rapid blood pressure reduction, hypertensive urgency patients should be treated with oral antihypertensive drugs to gradually lowering blood pressure and aim for blood pressure control within a few months.

\section{Limitation}

This study was not a randomized controlled study; therefore, there was a potential selection bias. There were some differences in patient characteristics in both groups, such as first-visit blood pressure and presenting symptoms, which could be potential confounders of the outcomes. Although we used these differences and others as identified factors affecting blood pressure level and revisit to adjust the outcomes, there might be some unknown, uncontrolled confounders; as a result, they might have an effect on blood pressure level and revisit. There is a possibility of incomplete data collection for patients that had a one-time visit at our hospital and revisit or followed up at another hospital because the Thailand hospital database is not linked between hospitals. A brief follow-up time may underestimate the efficacy of oral antihypertensive drugs on blood pressure control and adverse events. This study had good power to evaluate the primary outcomes, however, there was less power to demonstrate the differences of two secondary outcomes including MACE and blood pressure control within 2 weeks. A future study with longer follow-up period and larger sample will be appropriate to evaluate blood pressure control and MACE.

\section{Conclusion}

The use of oral antihypertensive agents has neither benefit nor risk in managing hypertensive urgencies in the emergency department. Oral hypertensive agents had no benefit in the reduction of blood pressure compared to managing without antihypertensive agents. There was no benefit in the reduction of the risk of 1 day-revisit or 7-day revisit with elevated blood pressure and no effect on the decrease in length of stay in the ED and blood pressure control within 2 weeks. Nonetheless, there were no identified complications of prescribing oral antihypertensive agents in managing hypertensive urgency.

\section{Disclosure}

The authors report no conflicts of interest for this work. 


\section{References}

1. The International Society of Hypertension (ISH). Background information on high blood pressure (hypertension); 2017. Available from: https://ish-world.com/public/background-info.htm. Accessed December 19, 2018

2. Health Data Center of Ministry of Public Health. NCD Report. Available from: https://hdcservice.moph.go.th. Accessed December 1, 2018.

3. Zampaglione B, Pascale C, Marchisio M, Cavallo-Perin P. Hypertensive urgencies and emergencies prevalence and clinical presentation. Hypertension. 1992;27(1):144-147. doi:10.1161/01. HYP.27.1.144

4. Williams B, Mancia G, Spiering W, et al. 2018 ESC/ESH Guidelines for the management of arterial hypertension. Eur Heart J. 2018;39 (33):3021-3104.

5. Salkic S, Batic-Mujanovic O, Ljuca F, Brkic S. Clinical presentation of hypertensive crises in emergency medical services. Mater Sociomed. 2014;26(1):12-16. doi:10.5455/msm.2014.26.12-16

6. McNaughton CD, Self WH, Zhu Y, Janke A, Storrow AB, Levy P. Incidence of hypertension-related emergency department visits in the United States, 2006-2012. Am J Cardiol. 2015;116(11):1717-1723. doi:10.1016/j.amjcard.2015.09.007

7. Oras P, Häbel H, Skoglund PH, Svensson P. Elevated blood pressure in the emergency department a risk factor for incident cardiovascular disease. Hypertension. 2020;75(1):229-236. doi:10.1161/ HYPERTENSIONAHA.119.14002

8. Whelton PK, Carey RM, Aronow WS, et al. 2017 ACC/AHA/ AAPA/ABC/ACPM/AGS/APhA/ASH/ASPC/NMA/PCNA

Guideline for the prevention, detection, evaluation, and management of high blood pressure in adults. J Am Society Hypertension. 2018;12(8):579.

9. James PA, Oparil S, Carter BL, et al. 2014 evidence-based guideline for the management of high blood pressure in adults report from the panel members appointed to the eighth joint national committee (JNC 8). JAMA. 2013.

10. Sánchez-Fabra D, Marinas Sanz R, Tarí Ferrer E, et al. Hypertensive urgencies: description of clinical characteristics, management, variables associated with re-entry and short-term prognosis. Hipertens Riesgo Vasc. 2018. https://www.ncbi.nlm.nih.gov/pubmed/30244994. (accessed 2018.
11. Patel KK, Young L, Howell EH, et al. Characteristics and outcomes of patients presenting with hypertensive urgency in the office setting. JAMA Intern Med. 2016;176(7):981-988. doi:10.1001/jamainternmed. 2016.1509

12. Kotruchin P, Mitsungnern $T$, Ruangsaisong $R$, Imoun $S$, Pongchaiyakul C. Hypertensive urgency treatment and outcomes in a northeast thai population: the results from the hypertension registry program. High Blood Press Cardiovasc Prev. 2018;25(3):309-315. doi:10.1007/s40292-018-0272-1

13. Gore J, Peterson E, Amin A, et al. Predictors of 90-day readmission among patients with acute severe hypertension. The cross-sectional observational Studying the Treatment of Acute hyperTension (STAT) study. Am Heart J. 2010;160(3):521-527. doi:10.1016/j.ahj.2010.06.032

14. Choi BG, Rha SW, Yoon SG, Choi CU, Lee MW, Kim SW. Association of major adverse cardiac events up to 5 years in patients with chest pain without significant coronary artery disease in the korean population. $J$ Am Heart Assoc. 2019;8:12. doi:10.1161/JAHA.118.010541

15. Menanga A, Edie S, Nkoke C, et al. Factors associated with blood pressure control amongst adults with hypertension in Yaounde, Cameroon: a cross-sectional study. Cardiovasc Diagn Ther. 2016;6 (5):439-445. doi:10.21037/cdt.2016.04.03

16. Orozco-Beltrán D, Brotons C, Moral I, et al. Factors affecting the control of blood pressure and lipid levels in patients with cardiovascular disease: the PREseAP Study. Rev Esp Cardiol. 2008;61 (3):317-321. doi:10.1157/13116661

17. Barreto MS, Matsuda LM, Marcon SS. Factors associated with inadequate blood pressure control in patients of primary care. Esc Anna Nery. 2016;20:1. doi:10.5935/1414-8145.20160016

18. Park SK, Lee DY, Kim WJ, et al. Comparing the clinical efficacy of resting and antihypertensive medication in patients of hypertensive urgency: a randomized, control trial. J Hypertens. 2017;35 (7):1474-1480. doi:10.1097/HJH.0000000000001340

19. Maloberti A, Cassano G, Capsoni N, et al. Therapeutic approach to hypertension urgencies and emergencies in the emergency room. High Blood Press Cardiovasc Prev. 2018;25(2):177-189. doi:10.1007/ s40292-018-0261-4

20. Saladini F, Mancusi C, Bertacchini F, et al. Diagnosis and treatment of hypertensive emergencies and urgencies among Italian emergency and intensive care departments. Results from an Italian survey: progetto GEAR (Gestione dell'Emergenza e urgenza in ARea critica). Eur J Intern Med. 2020;71:50-56. doi:10.1016/j.ejim.2019.10.004
Open Access Emergency Medicine

\section{Publish your work in this journal}

The Open Access Emergency Medicine is an international, peerreviewed, open access journal publishing original research, reports, editorials, reviews and commentaries on all aspects of emergency medicine. The manuscript management system is completely online and includes a very quick and fair peer-review system, which is all easy to use. Visit http://www.dovepress.com/testimonials.php to read real quotes from published authors. 